\title{
Human temporal bones versus mechanical model to evaluate three middle ear transducers
}

\author{
Christof Stieger, MSc; ${ }^{1 *}$ Hans Bernhard, MSc; ${ }^{2}$ Daniela Waeckerlin, BSc; ${ }^{3}$ Martin Kompis, MD, PhD; ${ }^{1}$ Juergen \\ Burger, PhD; ${ }^{3}$ Rudolf Haeusler, MD $^{1}$ \\ ${ }^{1}$ Department of Ear, Nose, and Throat, Head and Neck Surgery, Inselspital, University of Bern, Bern, Switzerland; ${ }^{2}$ Helbling \\ Technik Bern AG, Liebefeld, Switzerland; ${ }^{3}$ Department of Microtechnology, Berner Fachhochschule, Biel, Switzerland
}

\begin{abstract}
A life-size mechanical middle ear model and human temporal bones were used to evaluate three different middle ear transducers for implantable hearing aids: the driving rod transducer (DRT), the floating mass transducer (FMT) or vibrant sound bridge, and the contactless transducer (CLT). Results of the experiments with the mechanical model were within the range of the results for human temporal bones. However, results with the mechanical model showed better reproducibility. The handling of the mechanical model was considerably simpler and less time-consuming. Systematic variations of mounting parameters showed that the angle of the rod has virtually no effect on the output of the DRT, the mass loading on the cable of the FMT has a larger impact on the output than does the tightness of crimping, and the output level of the CLT can be increased by $10 \mathrm{~dB}$ by optimizing the mounting parameters.
\end{abstract}

Key words: anatomical model, hearing aids, implantable devices, laser Doppler vibrometry, middle ear, mounting parameter, rehabilitation, stapes displacement measurement, temporal bone, transducer.

\section{INTRODUCTION}

Hearing disorders due to acoustic trauma, e.g., from firearm use, genetic disorders, or as a part of the ageing process, are frequent. The consequences of hearing disorders, such as progressive isolation and withdrawal from social contacts, are serious. An estimated 16 percent of the U.S. population has hearing problems [1]. For several forms of hearing disorders, hearing aids are the preferred treatment method. Despite substantial progress in this area, conventional hearing aids still have a number of drawbacks, such as feedback, limited speech recognition due to residual distortions of the loudspeaker, or occlusion of the external auditory canal (EAC). Implantable hearing aids can potentially solve these problems. Over the past decades, different implantable hearing aids have been developed [2-6]. In conventional hearing aids, a miniature loudspeaker emits the amplified and preprocessed sound signal into the EAC. The ensuing pressure variations result in vibrations of the tympanic membrane (TM), which lead to movement of the ossicular chain of the middle ear (Figure 1). The sound is then transferred via the oval window (OW) to the cochlea, where the mechanical movement is transformed into a neural response transmitted by the auditory nerve. In contrast, implantable output transducers drive the ossicular chain directly and thereby stimulate the inner ear. Thus, implantable output transducers are equivalent to the

\footnotetext{
Abbreviations: CLT $=$ contactless transducer, DRT $=$ driving rod transducer, EAC = external auditory canal, FMT = floating mass transducer, IN = incus, OW = oval window, $\mathrm{ST}=$ stapes, $\mathrm{TM}=$ tympanic membrane.

*Address all correspondence to Christof Stieger, PhD; Inselspital, University of Bern, ENT Audiology, Bern, Switzerland 3010; +41-31-632-8789; fax: +41-31-632-3193.

Email: christof.stieger@dkf.unibe.ch

DOI: 10.1682/JRRD.2006.09.0114
} 


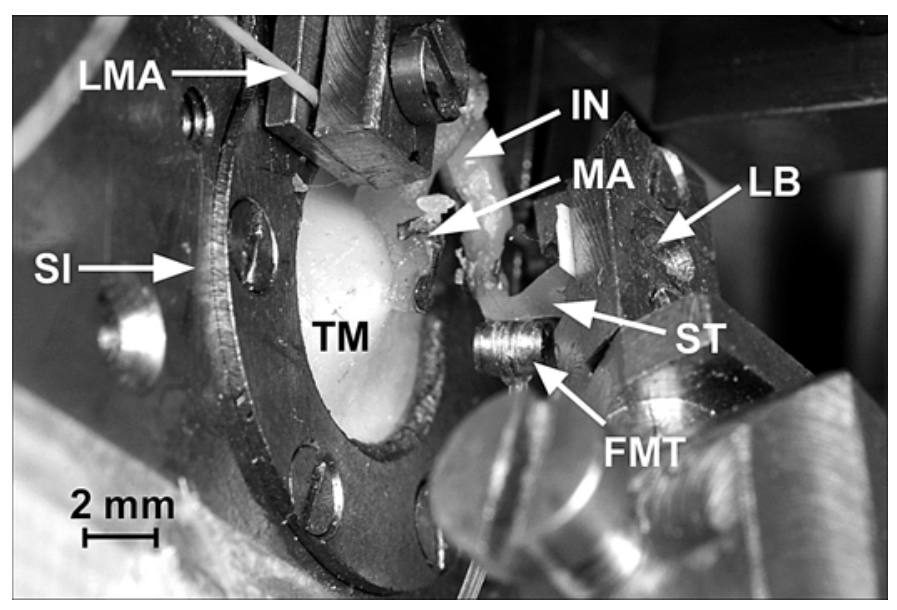

Figure 1.

Life-size mechanical middle ear model including tympanic membrane (TM), malleus (MA), incus (IN), stapes (ST), ligamentum mallei anterior (LMA), and ligamentum incudis posterior (not visible). Floating mass transducer (FMT) was attached to IN. Laser beam (LB) was directed to back side of footplate of ST. Sound input (SI) was applied through acoustically sealed chamber on reverse side of TM.

loudspeaker in conventional hearing aids and constitute key components of implantable hearing aids.

The evaluation of implantable transducers is an important and nontrivial part of the design and validation process. Output levels and frequency response have been measured and reported for different ear models. In simple mechanical, nonanatomical models [7], the entire middle ear structure is missing and the possibility of studying the impact of different mounting parameters is fundamentally limited. In contrast, human temporal bones [6-9], in vivo animals [8,10-11], or in vivo human subjects [12] are better models in terms of anatomy or estimation of the output levels [13-15]. However, the handling of such biological models is delicate and time-consuming. Furthermore, difficulties arise for studies involving systematic variations in mounting parameters because individual differences of more than $10 \mathrm{~dB}$ between temporal bones exist [15-17]. Finally, reuse and conservation time are limited [18]. A life-size mechanical middle ear model could reduce these drawbacks substantially and allow easier systematic measurements of different transducer designs.

In this study, a life-size mechanical middle ear model [19] was validated by comparative measurements in real human temporal bones. In addition, the influence of important mounting parameters of three different types of implantable hearing aid transducers was measured through systematic experimental variations.

\section{METHODS}

\section{Materials}

\section{Mechanical Middle Ear Model}

We used the physical, life-size mechanical middle ear model first presented by Taschke et al. [19]. This model consisted of three synthetic ossicles (malleus, incus [IN], and stapes [ST]), a TM, and three ligaments (ligamentum incudis posterior, ligamentum mallei anterior, and annular ligament) and was mounted on a baseplate (Figure 1). The TM was made of $0.1 \mathrm{~mm}$ silicon rubber. It was damped with a thin layer of Vaseline on the pars flaccida. The ossicles were made of a composite of epoxy resin and barite and had the average shape, size, and weight of human ossicles. The incudo-stapedial joint was modeled with a droplet of latex. Consequently, both the IN and ST could countershift in directions parallel to the stapedial footplate in accordance with the modes of vibration at the incudo-stapedial joint in the natural human middle ear [18]. The incudo-mallear joint was rigid. The annular ligament was represented by a thin foil made of silicon rubber $(0.1 \mathrm{~mm})$. A sound chamber $(2 \mathrm{~mL})$ corresponding to the EAC was mounted in front of the TM.

The coil of the contactless transducer (CLT) and the driver of the driving rod transducer (DRT) were attached to a small custom-built mounting unit. The permanent magnet of the CLT and the floating mass transducer (FMT) was directly crimped to the model IN and, in addition, fixed with a removable adhesive (Crystalbond $^{\mathrm{TM}}$ 555; Aremco Products, Inc, Valley Cottage, New York). The coupling rod of the DRT was attached to the ossicles with Crystalbond adhesive.

\section{Human Cadaver Temporal Bones}

Four fresh human temporal bones were harvested and preserved with a 1:10,000 Merthiolate solution, as described by Heiland et al. [18]. For acoustical measurements with a laser vibrometer, the laser beam was focused on the stapedial footplate. This allowed visual access to the middle ear cavity, which was obtained by means of a mastoidectomy, which is a common and routine surgical approach [18]. A $2 \mathrm{~mL}$ sound chamber was attached and fixed with cement (TempBond, Kerr Co, Orange, California) to the bony wall of the EAC.

For all temporal bones, measurements were first performed without an implantable transducer and then with an implanted transducer. The preparation for the acoustical 
measurement took approximately 2 hours and the implantation of the transducers an additional 1 to 2 hours.

All acoustical and transducer output measurements were performed in a climatic chamber at a temperature of $36{ }^{\circ} \mathrm{C} \pm 2{ }^{\circ} \mathrm{C}$ and a relative humidity above 99 percent to prevent dehydration of the temporal bone [20-21]. The use of human temporal bones and the study protocol were approved by the local ethical committee.

\section{Transducers}

Three different electromagnetic transducers were used: a DRT, a CLT, and an FMT (Figure 2). All transducers stimulated the inner ear by applying a force to the IN. The resulting vibrations were then conducted via the ST and OW to the inner ear.

The DRT (Figure 2(a)) was a custom-made device based on a similar principle as the commercially available MET ${ }^{\mathrm{TM}}$ transducer (Otologics Inc, Boulder, Colorado) [5] or the totally implantable cochlea amplifier [16]. The DRT generated a force within a hermetically sealed casing that was fixed to the mastoid (bony structure behind the EAC). Its output force was applied directly to one of the ossicles by means of a coupling rod (Figure 2(a)).

The CLT (Figure 2(b)) was based on a minimally invasive implantable electromagnetic transducer design, described in detail by Stieger et al. [22]. It consisted of a miniature disc-shaped coil (outer diameter $4.2 \mathrm{~mm}$, length $0.3 \mathrm{~mm}$ ) and a permanent magnet (samarium cobalt, diameter $3.2 \mathrm{~mm}$, length $0.3 \mathrm{~mm}$, axial magnetization). The coil was attached to the wall of the middle ear cavity and the magnet was fixed to the long process of the IN. A current applied to the coil induced a force on the magnet that vibrated the ST.

The FMT (Figure 2(c)) was a component of the commercially available Vibrant Soundbridge implantable hearing aid system (Vibrant Med-El, Innsbruck, Austria). It consisted of a moving permanent magnet inside of a coil. Because of the inertia of the mass of the magnet, the coil vibrated when an alternating current was applied. The FMT was attached via a crimp connection to the IN, where it vibrated the ossicular chain.

\section{Experimental Setting}

Laser Doppler vibrometry is a standard measurement method in middle ear and transducer research [16,18,21,2324] and was used to measure the displacement of the stapedial footplate in these experiments (Figure 3). Two different

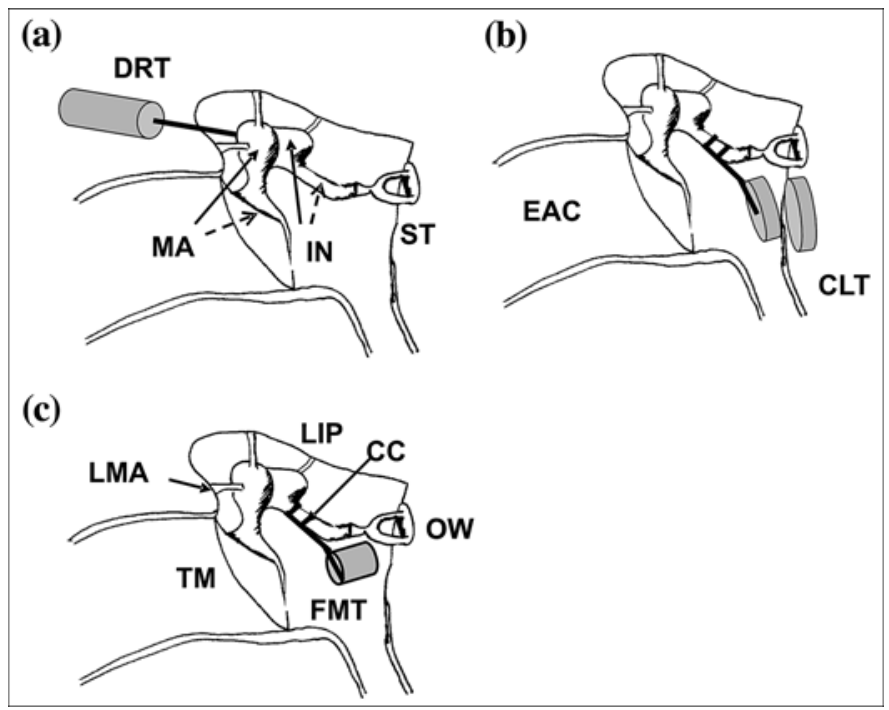

Figure 2.

Schematic view of three implantable hearing aid transducers. (a) Driving rod transducer (DRT) coupled to incus (IN) via rod. IN short process: solid line, IN lenticular process: dashed line. Malleus (MA) head: solid line, MA manubrium: dashed line. (b) Contactless transducer (CLT) consisting of coil attached to IN and permanent magnet attached to wall of middle ear cavity. (c) Floating mass transducer (FMT) attached to IN via crimp connection (CC). EAC = external auditory canal, $\mathrm{TM}=$ tympanic membrane, $\mathrm{ST}=$ stapes, $\mathrm{OW}=$ oval window, LIP = ligamentum incudis posterior, LMA = ligamentum mallei anterior.

types of measurements, acoustic excitation (Figure 3, labeled "b”), and transducer output measurements (Figure 3, labeled "a”), were performed.

For acoustic excitation, a standard setup with a loudspeaker and a probe microphone (ER-7, Etymotic Research, Elk Grove Village, Illinois) in an acoustic chamber connected to the EAC was used $[14,18]$. The acoustical characteristic was defined as the transfer function between an acoustical input at $90 \mathrm{~dB}$ SPL (sound pressure level) at the EAC and the ST displacement as measured by laser Doppler vibrometry.

The transducer output measurement was performed in the model ear and the human temporal bones and was defined as the transfer function between an electrical input of $1 \mathrm{~mW}$ of the transducer and the ST displacement as measured by laser Doppler vibrometry.

The stimulus signal was a sinus sweep between $100 \mathrm{~Hz}$ and 10,000 Hz. Signal analysis was performed in 21 consecutive third-octave bands within this range. 


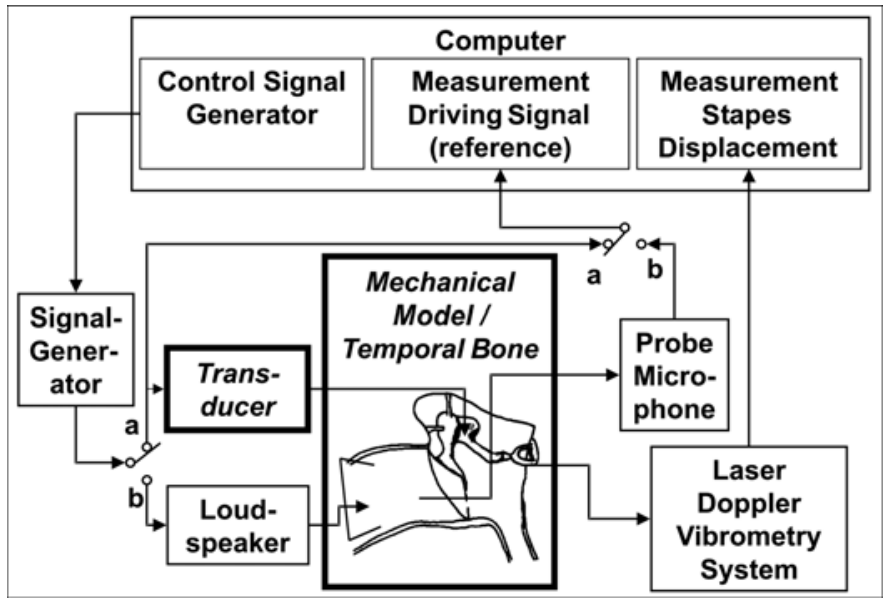

Figure 3.

Setup for measurements on temporal bones and mechanical middle ear. Signal generator drove either one of three transducers (labeled "a”) or loudspeaker (labeled "b”). For loudspeaker, reference signal was given by sound pressure level measured by probe microphone. Displacement of stapes was measured by laser Doppler vibrometry.

\section{Procedures}

\section{Comparison of Mechanical Middle Ear Model and Human Temporal Bones}

As a first step, the mechanical middle ear model was compared with human temporal bones. This evaluation included comparing results with acoustical excitation (Figure 3, labeled "b") and results on transducer output measurements (Figure 3, labeled "a”) from the literature and our own measurements.

The FMT was tested in the mechanical middle ear model and results were directly compared with the human temporal bone measurements previously reported by Winter et al. [13]. For the DRT and CLT, temporal bone measurements were performed because no such data are available in the scientific literature.

Because of anatomical variations, one implantation of the CLT had to be performed with a $0 \mathrm{~mm}$ offset between the axis of the coil and the permanent magnet and another with a $2 \mathrm{~mm}$ offset. For the DRT, no differences in the placement in each temporal bone were visible.

The acoustical measurements in human temporal bones were performed before implantation of the transducer to exclude effects of possible alterations due to the explantantion of the transducers. For the mechanical middle ear, the transfer functions were measured at the beginning and the end of each session.
Systematic Variation of Transducer Mounting Parameters Several mounting parameters were varied systematically in the mechanical middle ear model:

- For the DRT, the angle between the rod and the axis of the stapedial footplate was varied.

- For the CLT, the width of the air gap between coil and magnet and the angle between the axes of the coil and the magnet were varied.

- For the FMT, two parameters were varied: (1) the use or nonuse of adhesive additional to crimping and (2) the presence or absence of a moderate mass loading (150 mg) on the lead to the transducer at a distance of $4 \mathrm{~mm}$ from the FMT.

The ranges of all mounting parameters were chosen to represent realistic anatomical and surgical variations [25]. Exchanging a transducer took approximately 20 minutes. Changing a single mounting parameter took approximately 5 minutes.

\section{RESULTS}

\section{Comparison of Mechanical Middle Ear Model and Human Temporal Bones}

The comparative measurements between the mechanical middle ear model and the human temporal bones for acoustical stimulation were in good agreement with Taschke et al.'s earlier data for similar measurements [19]. For the mechanical middle ear model, the repeated measurements yielded virtually identical results (mean difference $1.0 \mathrm{~dB}$ ). In contrast, but in accordance with current literature [15-17,21], variations between measurements in different temporal bones were significantly larger (range from 5 to $27 \mathrm{~dB}$ between 200 and 5,000 Hz).

Figure 4 shows the comparison between the mechanical middle ear model and the human temporal bones for all transducers. The output measurement of the DRT appears in Figure 4(a). All measurements shared the same basic characteristics, i.e., they were flat up to approximately $500 \mathrm{~Hz}$ and then decreased with a slope of about $40 \mathrm{~dB}$ per decade for frequencies above $1,000 \mathrm{~Hz}$. They featured a resonance peak of approximately $10 \mathrm{~dB}$ around $800 \mathrm{~Hz}$. Displacements for the temporal bones were slightly higher than for the mechanical middle ear model for frequencies below $800 \mathrm{~Hz}$ (mean difference $7 \mathrm{~dB}$ ) and virtually identical (mean difference $<1 \mathrm{~dB}$ ) for frequencies between 1,250 and 5,000 Hz. The mean difference between the two separate measurements in the mechanical middle ear model was $<1 \mathrm{~dB}$. The difference between the two temporal bones was slightly larger (mean $4.8 \mathrm{~dB}$ ). 

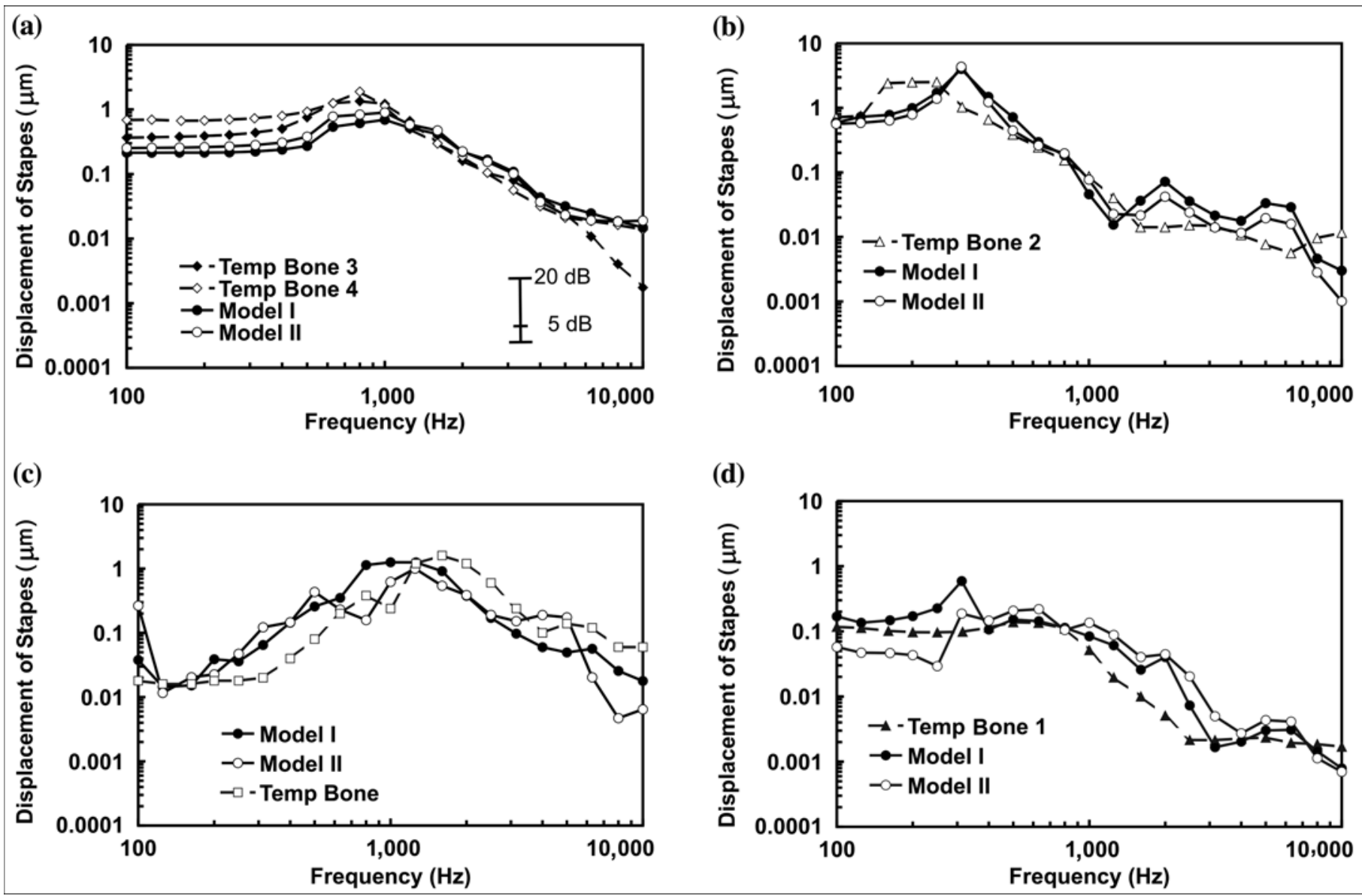

Figure 4.

Comparison of measurements in human temporal bones (Temp Bone) and life-size mechanical middle ear models for (a) driving rod transducer; (b) contactless transducer (CLT), shown with $0 \mathrm{~mm}$ offset; (c) floating mass transducer (FMT); and (d) CLT with $2 \mathrm{~mm}$ offset. Source (FMT Temp Bone): Winter M, Weber BP, Lenarz T. Measurement method for the assessment of transmission properties of implantable hearing aids. Biomed Tech (Berl). 2002;47(Suppl 1 Pt 2):726-27. [PMID: 12465286]

Figure 4(b) and (d) shows the output measurements for the CLT. For the first set of measurements (Figure 4(b)), the axes of the coil and the magnet were coincident $(0 \mathrm{~mm}$ offset). For both the human temporal bone and the mechanical middle ear model, amplitudes decreased by approximately $40 \mathrm{~dB}$ between 250 and 8,000 Hz. However, between 1,600 and $6,300 \mathrm{~Hz}$, the frequency response of the mechanical middle ear model was somewhat higher than that of the temporal bone. For the entire frequency range, the mean difference between the two measurements in the mechanical middle ear model was $<2 \mathrm{~dB}$.

The second set of measurements (Figure 4(d)) refers to the CLT with a $2 \mathrm{~mm}$ offset between the axes of the coil and permanent magnet. The transducer output in the temporal bone and the mechanical middle ear model showed a plateau around $0.1 \mu \mathrm{m}$ for frequencies below $800 \mathrm{~Hz}$. Between 800 and 10,000 Hz, the amplitude decreased by $40 \mathrm{~dB}$, similar to the $0 \mathrm{~mm}$ offset. Again, amplitudes in the mechanical middle ear model were somewhat higher in the range between 800 and 8,000 Hz. The mean difference between the mechanical middle ear measurements was small (1.2 dB).

Figure 4(c) shows the output measurements for the FMT. The amplitudes increased for frequencies below 800 by approximately $50 \mathrm{~dB}$ per decade, with a wide peak around 800 to $1,600 \mathrm{~Hz}$, and decreased by approximately $50 \mathrm{~dB}$ for higher frequencies. Amplitudes for the mechanical middle ear model tended to be somewhat higher for frequencies below $1,250 \mathrm{~Hz}$ and lower for frequencies in the range between 1,250 and 10,000 $\mathrm{Hz}$ compared with 
the temporal bone measurements, leading to a mean difference of $0.7 \mathrm{~dB}$ over the entire frequency range. Mean differences between the mechanical middle ear measurements were also $0.7 \mathrm{~dB}$.

\section{Systematic Variation of Transducer Mounting Parameters}

Systematic variations of transducer mounting parameters were performed in the mechanical middle ear model. Figure 5(a) shows the results of the output measurement of the DRT for systematic variation of the angle between the rod and the axis perpendicular to the ST. For the entire range of angles between $7^{\circ}$ and $37^{\circ}$, the output remained within a range of $6 \mathrm{~dB}$.
Figure 5(b) and (d) shows the output measurement of the CLT for systematic variations of the air gap and the angle between the axes of the coil and the permanent magnet, respectively. As the air gap between coil and magnet was widened from 0.2 to $1.2 \mathrm{~mm}$, the output decreased uniformly over the entire frequency range by an average of $10.5 \mathrm{~dB}$ (Figure 5(b)). Figure 5(d) shows that the maximal amplitude difference for variations of angles between the axes of the coil and the permanent magnet in the range of $0^{\circ}$ to $20^{\circ}$ was $2.6 \mathrm{~dB}$ (average over the entire frequency range). At $23^{\circ}$, contact between coil and magnet occurred, turning the transducer into a highly nonlinear system.

Figure 5(c) shows the output for the FMT for moderate crimping (i.e., crimping alone) and for tight crimping
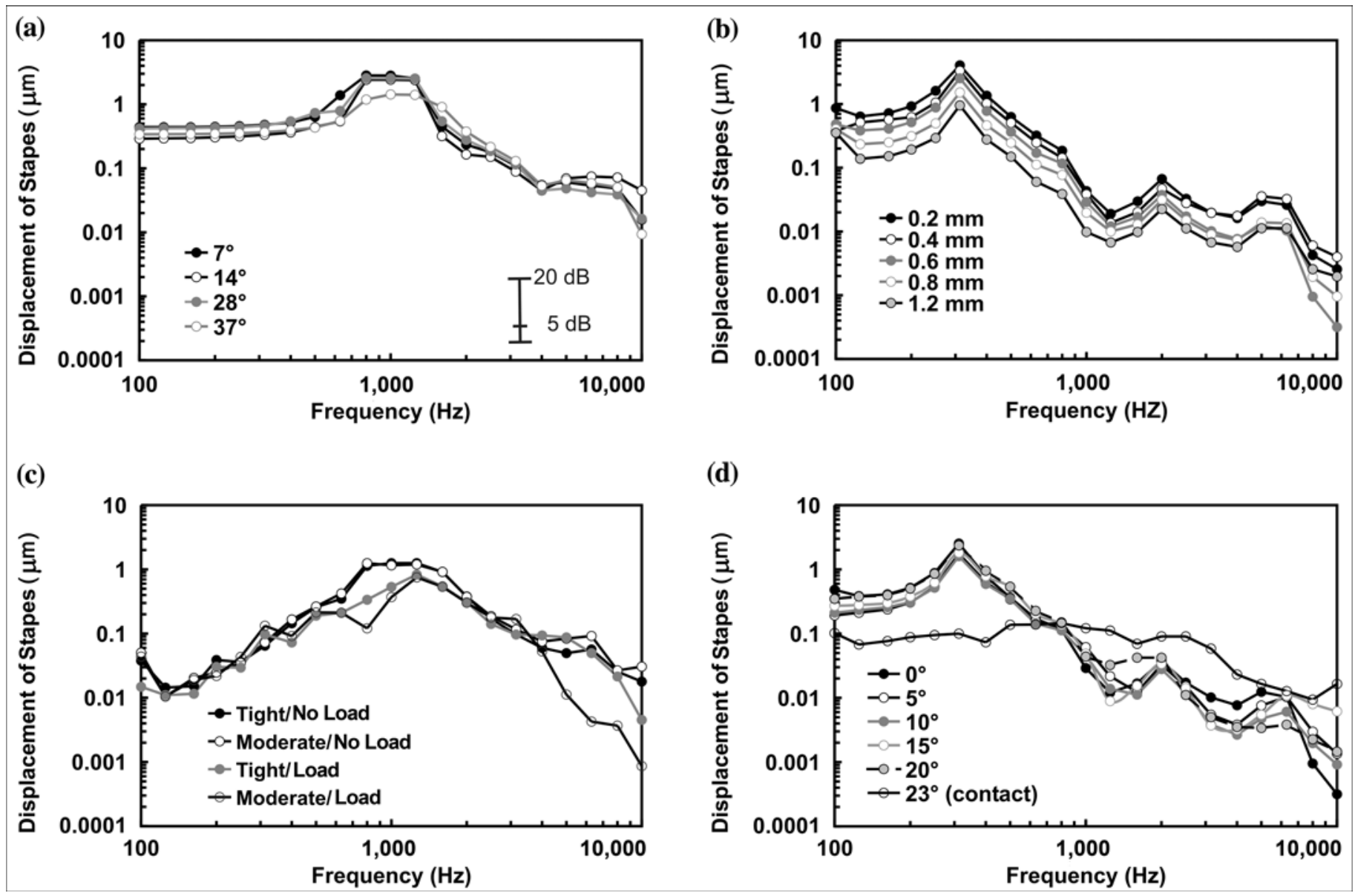

Figure 5.

Influence of systematic variations of mounting parameters on output of three transducers. (a) Driving rod transducer variations in angle between rod and axis perpendicular to stapes footplate, (b) contactless transducer (CLT) variations in air gap, (c) floating mass transducer variations in crimping (moderate vs tight) and loading (load vs no load), and (d) CLT variations in angle between axes of coil and permanent magnet. At $23^{\circ}$, contact between coil and magnet occurred. 
(i.e., crimping plus additional fixation with Crystalbond adhesive) when the cable from the transducer was hanging freely (no load) or loaded with $150 \mathrm{mg}$. Measurements for moderate and tight crimping with no load were virtually identical. For the loaded conditions, the amplitude was reduced between $700 \mathrm{~Hz}$ and $1,500 \mathrm{~Hz}$ by up to $10.0 \mathrm{~dB}$ for tight crimping and $18.9 \mathrm{~dB}$ for moderate crimping. For moderate crimping with load, another output reduction of up to $26.3 \mathrm{~dB}$ was observed at frequencies above $5,000 \mathrm{~Hz}$.

\section{DISCUSSION}

The main purpose of this study was to evaluate a mechanical middle ear model versus human temporal bones as a tool for investigating implantable middle ear transducers. The merit of this new tool is illustrated by examining the influence of different mounting parameters on the output of three implantable middle ear transducers.

The life-size mechanical middle ear model was found to be a useful instrument for this purpose. Preparation time for a single set of measurements was dramatically shorter than for human temporal bones. This difference is mainly because human temporal bones require extensive drilling and more time-consuming mounting of the transducers in a much more complex and limiting real anatomical environment. In contrast to human temporal bones, the mechanical middle ear model was available at any time and virtually for any duration. Furthermore, the mechanical model was found to be stable over extended time periods and repeated measurements were reproducible, confirming Taschke et al.'s results [19]. In contrast, even frozen human temporal bones can only be used for a limited time $[18,24]$ and interindividual variations on the order of a $10 \mathrm{~dB}$ magnitude occur, which is in agreement with previous reports [15-17,21].

The output of the DRT was almost invariant for the range of angles considered. The output can therefore be expected to be virtually independent of the individual implantation.

For the CLT, the output could be increased by up to $10 \mathrm{~dB}$ by reducing the air gap from $1.2 \mathrm{~mm}$ to $0.2 \mathrm{~mm}$. If the coil and the magnet were not coplanar, the angle between the two components had virtually no influence on the output level, as long as the magnet and the coil did not touch (Figure 5(d)). The influence of touching was highly nonlinear. Consequently, an optimal surgical placement (i.e., a small gap) is important because of the danger of direct contact. For practical applications, slightly larger gaps might therefore be preferable.

Results of the mechanical middle ear model confirmed results of a computer model [22] regarding the dependence of the expected output on the width of the air gap. However, this computer model alone could not predict the order of magnitude of nonlinearity when the two components of the system touched.

For the output of the FMT, the quality of crimping seemed to have virtually no influence on the output, which corresponds to Snik and Cremers' results [12]. They reported no significant changes in five of six frequencies between $250 \mathrm{~Hz}$ and $6,000 \mathrm{~Hz}$ when cement was used for additional fixation. According to our results, the load on the electrical cable has a higher impact on the output of FMT than does the use of additional adhesive for crimping.

Our results allow direct comparison of different transducer designs (Figure 4). In this comparison, the FMT generates smaller displacements at low frequencies (below $800 \mathrm{~Hz}$ ), which corresponds to one limitation of the current audiological indication [26]. The CLT generates lower displacements than the other two transducer types in the frequency range between $1,000 \mathrm{~Hz}$ and $3,000 \mathrm{~Hz}$. The DRT tends to be the most efficient transducer over almost the entire frequency range.

\section{CONCLUSIONS}

Implantable hearing aid transducers can be evaluated with a life-size mechanical middle ear model [19]. Compared with tests that use human temporal bones, the handling was simpler and less time-consuming. Furthermore, systematically varying individual parameters was easier than with human temporal bones. Results from the mechanical middle ear model and from human temporal bones were in reasonable agreement with all three of the transducer designs considered in this research.

\section{ACKNOWLEDGMENTS}

We would like to thank Dr. H. Hudde, Ruhr-Universität Bochum, Germany, for the life-size model of the human middle ear, and Ms. E. Clamann and Dr. S. John for their help in preparing this article. 
Daniela Waeckerlin is now with Medela AG, Medical Technology, Baar, Switzerland.

This article is based on research performed by Christof Stieger for a doctoral degree received January 11, 2007.

This material was based on work supported by the Commission for Technology and Innovation, Berne, Switzerland (grant 5665.1 MTS) and the Gebert Rüf Foundation, Basel, Switzerland (grant P-007/01).

The authors have declared that no competing interests exist.

\section{REFERENCES}

1. Lethbridge-Çejku M, Rose D, Vickerie J. Summary health statistics for U.S. adults: National health interview survey, 2004. Hyattsville (MD): U.S. Department of Health and Human Services, Centers for Disease Control, National Center for Health Statistics; 2006.

2. Chen DA, Backous DD, Arriaga MA, Garvin R, Kobylek D, Littman T, Walgren S, Lura D. Phase 1 clinical trial results of the Envoy System: A totally implantable middle ear device for sensorineural hearing loss. Otolaryngol Head Neck Surg. 2004;131(6):904-16. [PMID: 15577788]

3. Hough JV, Dyer RK Jr, Matthews P, Wood MW. Semiimplantable electromagnetic middle ear hearing device for moderate to severe sensorineural hearing loss. Otolaryngol Clin North Am. 2001;34(2):401-16. [PMID: 11382578]

4. Huttenbrink KB. Current status and critical reflections on implantable hearing aids. Am J Otol. 1999;20(4):409-15. [PMID: 10431878]

5. Kasic JF, Fredrickson JM. The Otologics MET ossicular stimulator. Otolaryngol Clin North Am. 2001;34(2):501-13. [PMID: 11382583]

6. Ball GR, Culp JM, Mar C, Dietz T, Salisbury JD, inventors; Symphonix Devices, Inc, assignee. Implantable and external hearing systems having a floating mass transducer. United States patent US 5857958. 1999 Jan 12.

7. Leysieffer H, Baumann JW, Muller G, Zenner HP. An implantable piezoelectric hearing aid transducer for inner ear deafness. II: Clinical implant [in German]. HNO. 1997;45(10):801-15. [PMID: 9445853]

8. Ko WH, Zhu WL, Kane M, Maniglia AJ. Engineering principles applied to implantable otologic devices. Otolaryngol Clin North Am. 2001;34(2):299-314. [PMID: 11382572]

9. Needham AJ, Jiang D, Bibas A, Jeronimidis G, O’Connor AF. The effects of mass loading the ossicles with a floating mass transducer on middle ear transfer function. Otol Neurotol. 2005;26(2):218-24. [PMID: 15793408]
10. Javel E, Grant IL, Kroll K. In vivo characterization of piezoelectric transducers for implantable hearing aids. Otol Neurotol. 2003;24(5):784-95. [PMID: 14501457]

11. Plinkert PK, Baumann JW, Lenarz T, Keiner S, Leysieffer $\mathrm{H}$, Zenner HP. In vivo studies of a piezoelectric implantable hearing aid transducer in the cat [in German]. HNO. 1997;45(10):828-39. [PMID: 9445855]

12. Snik A, Cremers C. Audiometric evaluation of an attempt to optimize the fixation of the transducer of a middle-ear implant to the ossicular chain with bone cement. Clin Otolaryngol Allied Sci. 2004;29(1):5-9. [PMID: 14961845]

13. Winter M, Weber BP, Lenarz T. Measurement method for the assessment of transmission properties of implantable hearing aids. Biomed Tech (Berl). 2002;47(Suppl 1 Pt 2):726-27. [PMID: 12465286]

14. Gan RZ, Wood MW, Ball GR, Dietz TG, Dormer KJ. Implantable hearing device performance measured by laser Doppler interferometry. Ear Nose Throat J. 1997;76(5): 297-99,302,305-9. [PMID: 9170711$]$

15. Huber A, Linder T, Ferrazzini M, Schmid S, Dillier N, Stoeckli S, Fisch U. Intraoperative assessment of stapes movement. Ann Otol Rhinol Laryngol. 2001;110(1):31-35. [PMID: 11201805]

16. Leysieffer $\mathrm{H}$. Principle requirements for an electromechanical transducer for implantable hearing aids in inner ear hearing loss. I: Technical and audiologic aspects [in German]. HNO. 1997;45(10):775-86. [PMID: 9445850]

17. Nishihara S, Goode R. Measurements of tympanic membrane vibrations in 99 human ears. In: KB Huttenbrink, editor. Proceedings of the International Workshop on Middle Ear Mechanics in Research and Otosurgery; 1996 Sep 19-22; Dresden, Germany. Dresden (Germany): Bibliothek der HNO-Universitatsklinik; 1997. p. 91-95.

18. Heiland KE, Goode RL, Asai M, Huber AM. A human temporal bone study of stapes footplate movement. Am J Otol. 1999;20(1):81-86. [PMID: 9918179]

19. Taschke H, Weistenhoefer C, Hudde H. A full-size physical model of the human middle ear. Acustica/Acta Acustica. 2000;86:103-16.

20. Eiber A, Kauf A, Maassen MM, Burkhardt C, Rodriguez J, Zenner HP. First comparisons with laser vibrometry measurements and computer simulation of ear ossicle movements [in German]. HNO. 1997;45(7):538-44. [PMID: 9340336]

21. Voss SE, Rosowski JJ, Merchant SN, Peake WT. Acoustic responses of the human middle ear. Hear Res. 2000;150(1-2): 43-69. [PMID: 11077192]

22. Stieger C, Wackerlin D, Bernhard H, Stahel A, Kompis M, Hausler R, Burger JJ. Computer assisted optimization of an electromagnetic transducer design for implantable hearing aids. Comput Biol Med. 2004;34(2):141-52. [PMID: 14972633] 
23. Stenfelt S, Hato N, Goode RL. Factors contributing to bone conduction: The middle ear. J Acoust Soc Am. 2002;111(2): 947-59. [PMID: 11863197]

24. Vlaming MS, Feenstra L. Studies on the mechanics of the reconstructed human middle ear. Clin Otolaryngol Allied Sci. 1986;11(6):411-22. [PMID: 3815866]

25. Stieger C, Djeric D, Kompis M, Remonda L, Hausler R. Anatomical study of the human middle ear for the design of implantable hearing aids. Auris Nasus Larynx. 2006;33(4): 375-80. [PMID: 16704912]
26. Fraysse B, Lavieille JP, Schmerber S, Enee V, Truy E, Vincent C, Vaneecloo FM, Sterkers O. A multicenter study of the Vibrant Soundbridge middle ear implant: Early clinical results and experience. Otol Neurotol. 2001;22(6):952-61. [PMID: 11698825]

Submitted for publication September 22, 2006. Accepted in revised form February 14, 2007. 